\title{
Reescrituras do Cristo: Modelos de narração nas origens e além
}

\author{
Rewritings of Christ: Models of \\ narration at the origins and beyond
}

Texto enviado em

06.04.2020

e aprovado em

24.04.2020

V. $10-$ N. $20-2020$

* Doutorado em Theologie pelo Ruprecht-Karls-

Universität Heidelberg (Alemanha), docente do PPG-Ciências da Religião

da PUC-Campinas, pesquisador produtividade CNPq, nível 2. E-mail: profpaulonogueira@ outlook.com.br

\section{Paulo Augusto de Souza Nogueira}

"Há, porém, muitas outras coisas que Jesus

$\mathrm{fez}$, as quais se fossem escritas uma a uma, não poderia o mundo todo conter os livros que seriam escritos". (Evangelho de João 21,25) ${ }^{1}$

\section{Resumo}

Este artigo propõe a supressão da divisão estrita entre estudos bíblicos e estudos de recepção, entre fontes originais e recriações literárias. Esta divisão privilegia a exegese bíblica como guardiã da archê, do princípio, do original. Argumentamos que os Evangelhos mesmo os mais antigos dentre eles - já oferecem narrativas articuladas de memórias sobre Jesus. Os instrumentos de construção de mundo operantes na narrativa já se faziam presentes nas primeiras tradições. A pluralidade de modelos de apresentação da vida de Jesus, testemunhada em textos canônicos e apócrifos, não nos permite entender o modelo marcano, de narrativa centrada na morte do herói, como único, nem mesmo o mais antigo.

1. Tradução minha. 
Textos como a Fonte dos Ditos de Jesus (Fonte Q) e o Evangelho de Tomé, que contém apenas ditos de Jesus, nos indicam que Jesus era compreendido por comunidades antigas como sendo antes de tudo um profeta ou um mestre de sabedoria. Por outro lado, a centralidade da morte do herói, do modelo de evangelho marcano, se desenvolveu para além de narrativas sobre Jesus, colaborando para o desenvolvimento de outros gêneros que narram o sofrimento dos apóstolos e até de cristãos e cristãs comuns. Também insistimos no dinamismo dos processos criativos de produção de reescrituras do Cristo, no passado (nos evangelhos do Novo Testamento, nos evangelhos apócrifos) e no presente (nas artes, na cultura popular). Por fim fizemos referência ao potencial de criação, bricolagem e atualização dos leitores contemporâneos das diferentes releituras do Cristo, compondo entre as tradições religiosas, as práticas religiosas populares e a cultura de massa.

\section{Palavras-chave: Evangelhos, Evangelhos Apócrifos, Reescrituras do Cristo, Recepção da Bíblia.}

\section{Abstract}

This article argues for the suppression of the strict division between the biblical studies and the reception studies, between original sources and literary recreations. This division favors biblical exegesis as a guardian of the origins (archê). We argue that the Gospels - even the most ancient of them - offer articulated accounts of the memories about Jesus. The instruments of world construction that operate in the narrative were operating from the beginning. The plurality of models of giving an account of Jesus' life, witnessed in canonical as well as in apocryphal texts, don't allow us to understand the Marcan model, of the account centered in the hero's death, as unique and even the most ancient. Texts as the Sayings Gospels $(Q)$ and the Gospel of Thomas, which consist only of sayings, show us that Jesus was understood by ancient communities as a prophet or a wisdom teacher. On the other side, the centrality of the hero's death, according to Marks model has developed beyond accounts about Jesus, collaborating for the development of other literary genres that give an account of the suffering of the apostles and even average Christians. We also insist on the dynamics of creative processes in the production of rewritings of Christ, in the past (in the New Testament Gospels and in the Apocryphal Gospels) and today (in the art, in the popular culture). And finally, we highlighted the potential of creativity, of bricolage, and of renewing by the contemporary readers of the different rereadings of Christ, moving across diverse religious traditions, religious practices, and mass media symbols.

Keywords: Gospels, Apocryphal Gospels, Rewriting of Christ, Reception of the Bible 


\section{Introdução}

figura emblemática de Jesus de Nazaré, além de ser tema de constante reflexão de religiosos, clérigos ou teólogos, de distintas confissões, recebe renovada atenção de narradores, poetas, pintores e cineastas. Os agentes culturais não resistem ao fascínio de sua figura emblemática e multifacetada, o que provoca atualizações nos mais diferentes formatos artísticos. Das emblemáticas narrativas como $\mathrm{A}$ Tentação de Cristo, de Kazantzákis (2015) e o Evangelho Segundo Jesus Cristo, de Saramago (1991), em filmes como Je Vous Salue, Marie ${ }^{2}$, até o recente e controverso desfile da Mangueira, que tinha por título A verdade vos fará livres ${ }^{3}$, passando por muitas recriações do âmbito popular e doméstico que mal chegamos a ter conhecimento, é quase impossível não se ver compelido a atualizar o símbolo e o personagem Jesus de Nazaré, fazê-lo dialogar com a nossa realidade, com o nosso mundo. Como nosso mundo é plural, assimétrico e fragmentado, assim também dele emergem imagens do Cristo das mais plurais e fragmentadas.

As discussões sobre teologia e literatura se constituíram num fértil campo de trabalho acadêmico que está sintonizado e capacitado, por meio das mais diversas abordagens, a rastrear essas recriações do Cristo na poesia, na narrativa, nas artes cênicas, no cinema, entre outros. Seja por meio da crítica literária, dos estudos discursivos, da teologia da arte, dos estudos de recepção ou da teopoética, pesquisadores de diferentes campos do saber valorizam essas narrativas em seu contexto estético, social e teológico. Desta forma, se constituiu e se organizou um campo de estudos vibrante e promissor capaz de analisar a atualização de temas, enredos, personagens e símbolos da Bíblia, no caso, do campo simbólico e narrativo em torno a Jesus de Nazaré. Esta área de estudos, no entanto, se vê relacionada com outra que lhe é anterior, que se porta como um preservador da archê, do princípio e origem, que demandaria

2. Direção de Jean-Luc Godard, 1986.

3. www.mangueira.com.br, acessado em 25/04/2020. 
outra abordagem, outra disciplina, com outros procedimentos metodológicos. Ao falarmos de disciplinas, seja as da origem, seja as da recepção, as posteriores, entramos num dos grandes vespeiros das ciências humanas do século XXI, e nelas das Ciências da Religião. Reconhecemos que o mundo é complexo, que a velocidade das transformações culturais é acelerada, mas ainda pensamos o mundo por gavetas científicas, com credenciais, cadeiras ortodoxas de formação do pesquisador, vocabulário distintivo, veículos de divulgação exclusivos, abrigos institucionais, etc. Mantemos, portanto, uma relação esquizofrênica com a consciência de necessitarmos de interação e colaboração de diversas abordagens em torno a complexos simbólicos, mas nosso trabalho segue disciplinar, delimitando com rigor competências e abordagens. Nesse contexto, a tarefa de estudar as reescrituras do Cristo fica submetida ao olhar desconfiado do pesquisador que teme que muitas fronteiras sejam cruzadas, como exegese bíblica, teologia, história cultural, estudos literários, estudos discursivos, teoria da narrativa, cultura visual, etc. No âmbito da própria área de conhecimento Ciências da Religião e Teologia há uma cisão fundamental, às vezes instransponível: o estudo de Jesus de Nazaré e do Cristo nos estudos bíblicos, e seu estudo complementar na história das ideias e na recepção nas culturas, entre elas, suas reescrituras na literatura. Uma cisão entre a archê e o depois, entendido como de segunda mão. Nosso objetivo neste artigo é propor e argumentar a favor de uma abordagem unificada, nem por isso menos exigente, dos processos de recriação do Cristo, em uma perspectiva que problematize as origens como recriação. Nosso pressuposto é que qualquer articulação textual, nas suas mais diversas formas, já representa uma moldagem do que se descreve, narra, canta, pinta, imagina.

Já propusemos em outro texto que o papel do exegeta no século XXI deva ser reconfigurado para o de um crítico da relação religião e cultura; não mais um guardião de fatos históricos originais, tampouco de interpretações autorizadas, para se permitir entrar nos complexos e surpreendentes jogos de interpretação, apropriação e recriação dos 
símbolos religiosos na cultura (NOGUEIRA, 2012). Para fazê-lo vamos às primeiras narrativas sobre Jesus de Nazaré com o intuito de demonstrar que já ali havia recepção e reapropriação, reescrituras, portanto, em função de contextos e horizontes de expectativas de leitores e leitoras comuns. Comuns, porém criativos, da cultura popular do Mediterrâneo.

Neste artigo nos propomos a discutir os evangelhos, mesmo os mais antigos, como reescrituras, como primeiras tentativas de dar forma narrativa à memória do Cristo para as primeiras comunidades cristãs. Nesses esforços todas as articulações da elaboração narrativa estão em ação, como a escolha de actantes, de tempo, lugar, modelos de ação, hipóteses causais, perspectiva, seleção e combinação de materiais, com a consequente ação de esquecimento de outros. Essas primeiras narrativas são reelaborações da tradição oral, que por sua vez assim já procedeu com as memórias de Jesus, interpretando-as. Partimos do pressuposto que não há acesso ao mundo sem o uso de esquemas narrativos de cognição e de interpretação, etc (BOYD, 2009; TURNER, 1996). Também apresentaremos o problema da pluralidade de modelos de evangelhos, sendo que cada um deles privilegia um tipo de construção narrativa. Por fim, enfatizaremos a necessidade de entendermos o profundo vínculo criativo nas narrações sobre Jesus que unem o material do Novo Testamento, as narrativas apócrifas, os outros gêneros que emprestam elementos da tradição dos evangelhos para narrar e articular a experiência de sofrimento dos cristãos (como os Atos Apócrifos, as Atas dos Mártires e as Vidas dos Santos), e as recriações artísticas da vida de Jesus em todos os gêneros (poesia, novela, teatro, cinema, etc.) e na cultura popular (rituais, rezas, incorporações, etc.). Não se trata de diluir o termo reescritura, mas de tomarmos consciência que os processos de interpretação são dinâmicos, criativos, compulsórios e que perpassam os nossos esforços de explorar renovados sentidos em Jesus de Nazaré para o nosso tempo, da mesma forma como o fizeram as primeiras gerações. 


\section{A provocação que veio do Eufrates...}

\section{Um evangelho sem enredo?}

O Evangelho de Tomé é um dos textos mais importantes da coleção que se convencionou chamar de Evangelhos Apócrifos. A despeito de não ser canônico, ele é um dos evangelhos mais antigos, podendo ser datado em torno do ano 100 d.C., provavelmente mais antigo, portanto, que o Evangelho de Lucas ou que o Evangelho de João. Até a descoberta dos textos de Nag-Hammadi, em 1945, ele era conhecido por fragmentos e por citações coletadas dos pais da igreja. Com a descoberta da Biblioteca da Nag-Hammadi, em 1945, no entanto, temos acesso a todo o texto copta. O Evangelho de Tomé é constituído de 114 ditos (logia) de Jesus. Já na apresentação do Evangelho, Jesus se oferece ao seu leitor como aquele cujas palavras têm que ser interpretadas. "Quem quer que descubra a interpretação destas sentenças não provará a morte" (1) ${ }^{4}$. A inserção dessa sentença no começo de uma coleção de ditos sugere o modo como elas devem ser lidas. Uma vez interpretadas as palavras, o leitor pode viver eternamente. Parece que temos aqui um caso de salvação pela interpretação, ou melhor, por união mística ao Cristo por meio da compreensão profunda de suas palavras. Essa experiência mística é sugerida pelas metáforas "ficar perturbado", "ficar maravilhado", conforme sugere o dito seguinte: “Jesus disse: Que aquele que procura não deixe de procurar até que encontre. Quando encontrar, ficará perturbado. Quando estiver perturbado, ficará maravilhado e dominará tudo" (2). O Evangelho de Tomé é tomado de uma aura místico-dualista, que os especialistas relacionam com uma tendência filosófica-popular de fundo médio-platônico. Os ditos de Jesus são tomados por estrutura de linguagem dualista e por estilo enigmático. O objetivo é adentrar em um nível de compreensão secreto, profundo, iniciático com aquele que pronuncia os ditos, o Jesus vivente. Tornar-se um solitário (monachos), superar a divisão, a dualidade ou ascender, são imagens usadas para indicar o novo estado do que se engaja

4. Citações e referências ao Evangelho de Tomé segundo: MEYER, M. O Evangelho de Tomé. As sentenças ocultas de Jesus. Rio de Janeiro: Imago, 1993. 
na interpretação profunda das palavras de Jesus.

O Evangelho de Tomé apresenta um problema para a pesquisa das tradições mais antigas sobre Jesus. Ele não narra, na verdade ignora, toda e qualquer referência à morte e ressurreição de Jesus. $\mathrm{Na}$ verdade, nem sequer seus milagres e demais ações são narradas neste evangelho. Ou seja, estamos diante de um evangelho dos mais antigos que não vê qualquer motivo para dar narrativa aos milagres, às viagens, conflitos com as autoridades e à paixão e ressurreição de Jesus. Nada disso parece interessar ao texto e, portanto, à experiência de união mística com o Cristo por meio da correta (diga-se, profunda) interpretação de seus ditos. As palavras de Jesus são o que importa, não as suas ações, mesmo as que se consideram ações salvíficas. Teologicamente o Evangelho de Tomé apresenta um problema espinhoso: como é possível que um evangelho de tanta antiguidade ofereça uma interpretação de Jesus de Nazaré sem referência a suas ações, seus milagres, relação com a história, com as instituições judaicas e romanas, e que sequer mencionem o que o cristianismo nascente considerava o centro de sua ação, sua morte e ressurreição? Não era o Jesus que morre e ressuscita o centro do anúncio (kerigma) da comunidade de Antioquia e, portanto, da missão paulina? Não é o Cristo crucificado o centro da pregação de Paulo e sua morte e ressurreição o fundamento da salvação dos cristãos, que é evocado no batismo? O que fazer com essa ausência de referência à morte de Jesus para o perdão de pecados?

Alguém poderia responder a esse desconforto dizendo que o evangelho de Tomé não é representativo, em termos teológicos, do cristianismo mainstream, ortodoxo, uma vez que ele era de caráter gnóstico e docético. De fato o Jesus apresentado pela tradição de Tomé pode ser menos representativo em certas áreas importantes da expansão cristã nos dois primeiros séculos, como a Ásia Menor, Macedônia, Acaia e Roma. No entanto, a tradição de Tomé é central e muito influente no cristianismo do leste da Síria e, depois, no Egito. É tudo uma questão de definir o que é centro e o que é periferia, para se avaliar a represen- 
tatividade de ideias teológicas nas origens do cristianismo. Também é necessário considerar se o uso de conceitos como "gnóstico" e "docético" se aplicam de forma adequada ao Evangelho de Tomé. Depois da descoberta dos textos de Nag-Hammadi os pesquisadores evitam o uso indiscriminado do conceito "gnóstico". Tomé, por exemplo, não reflete sistemas gnósticos de qualquer tipo e o dualismo que expressa poderia ser encontrado em outros textos do cristianismo primitivo, a começar com o Evangelho de João (KLAUCK, 2007, p.135).

O desconforto apresentado pelo Evangelho de Tomé talvez possa ter raizes mais antigas e mais profundas. E se ele não fosse o primeiro evangelho a desconsiderar a centralidade das ações de Jesus de Nazaré, não dando a tradicional importância à sua morte e ressurreição?

$\mathrm{Na}$ verdade o problema de um evangelho sem enredo, de um Cristo que não é organizado narrativamente por meio de relatos ordenados, e que tenha como centro a sua morte e ressurreição, é mais antigo que o Evangelho de Tomé. Trata-se de uma fonte de ditos de Jesus que subjaz aos evangelhos de Mateus de de Lucas, conhecido como Fonte $Q(Q$, vem de Quelle, "fonte", em alemão). Há um conjunto significativo de materiais sobre Jesus de Nazaré que existem paralelamente em Mateus e em Lucas, mas que faltam a Marcos, o evangelho mais antigo dos sinóticos. Ou seja, o fato de estar preservado nesses evangelhos e não em Marcos foi explicado na teoria das duas fontes por meio da hipótese de que havia uma fonte independente e talvez mais antiga que Marcos. Essa fonte, curiosamente, é constituída quase que exclusivamente por ditos de Jesus. Esses ditos são diferentes dos de Tomé. Ali Jesus não é o ressuscitado e o tom das mensagens não é tão exotérico, dualista e misterioso como em Tomé. Parece que o material da Fonte $Q$ é de muita antiguidade e que seu arranjo em uma coleção de sentenças antecede a organização da primeira tradição de Jesus no esquema pascal. Ou, o que é mais surpreendente. Revelaria que a organização das tradições de Jesus em torno ao esquema morte- 
-ressurreição é secundário.

A pesquisa sobre a Fonte $Q$ teve um avanço muito grande nos anos 90 , principalmente na escola de Claremont, entre outros ${ }^{5}$. Nesse período foram produzidas muitas obras sobre a Fonte $Q$, também chamada de Evangelho dos Ditos (Sayings Gospel). Não faltou inclusive uma resposta latino-americana, que produziu artigos em RIBLA e ensaiou, por algum tempo, chamar essa fonte de "Evangelho Radical" (VAAGE, 1995). Também foram produzidas pesquisas e teses doutorais sobre a Fonte $\mathrm{Q}$. Dentre elas se destaca a de Luigi Schiavo que analisa a fonte $Q$ na perspectiva do mito de combate apocalíptico, da luta entre Jesus e o Diabo (SCHIAVO, 2003). Na versão lucana $Q$ se inicia com a cena da vitória de Jesus contra o Diabo nas tentações do deserto (Lucas 4). Schiavo se pergunta pela função dessa cena num evangelho que deveria ser caracterizado como uma coleção de ditos. A solução encontrada foi interpretar a tentação como uma espécie de vitória de Jesus pela palavra, afinal ele vence o Diabo por três vezes citando as Escrituras, o que o qualificaria como o mestre vitorioso, habilitado a ensinar e profetizar com autoridade. Esta interpretação inverte, portanto, a leitura sinótica marcana tradicional, de que o ápice da vida e atuação de Jesus seja seu sacrifício e vitória na cruz, sendo seu ensino uma espécie de preparação para esse evento. A tentação de Jesus na fonte $Q$ seria a vitória definitiva e irrevogável de Jesus contra o Diabo, que já teria seu destino selado e definido. Jesus prepara então seus discípulos para o seguimento e a missão a partir desse fundamento.

A pesquisa sobre a Fonte $Q$ teve muitos outros desdobramentos e debates, a que não podemos nos referir aqui. Não há um consenso sobre se a Fonte $\mathrm{Q}$ se constituiu apenas de uma fonte antiga, incorporada aos evangelhos de Mateus e de Lucas, ou se chegou a se constituir num

5. Podemos citar como obras de referência dessa pesquisa, entre outras, VAAGE, L, Galilean Upstarts. Jesus'First Followers According to Q. Valley Forge: Trinity Press International, 1994 e MACK, B. O Evangelho perdido: o livro de Q e as origens cristãs. Rio de Janeiro: Imago, 1994. 
evangelho e que tenha circulado de forma independente por um certo período. No entanto, o fato de encontrarmos uma disposição dos ditos, com uma introdução que lhe dá um enquadramento narrativo, que determina a leitura de todo o restante do material nos indica que as primeiras gerações cristãs produziam reescrituras de Jesus de Nazaré. A Fonte $Q$ não é compilação pura e simples de ensinamentos de Jesus, ela é antecedida de um relato de caráter mítico, do âmbito do mito de combate, que insere todo o seu ensinamento num contexto de revelação do final dos tempos, de tempos de crise escatológica. Jesus venceu o Diabo por meio da palavra, da Escritura, por isso seus seguidores também o poderão vencer, se estiverem comprometidos com o ensinamento de seu profeta.

O Evangelho de Tomé e a Fonte dos Ditos de Jesus, a Fonte Q, nos desafiam, portanto, a concepção de que o modelo sinótico seja o primeiro, o original, de uma história de Jesus de Nazaré centrada no destino e na ação de Jesus como o que morre e ressuscita, narrativa que dá sentido à afirmação soteriológica central do cristianismo nascente: do anúncio (kerigma) do messias que morre e ressuscita para a salvação do mundo. O modelo proposto por essas duas obras, guardadas as enormes diferenças entre ambas, é que Jesus pode sim ser interpretado a partir de outros eixos igualmente significativos e importantes para a vida dos primeiros cristãos. Eles têm em comum o fato de que Jesus é um mestre de sabedoria, que seus ensinamentos não somente representam o que é mais importante do seu legado, mas que sua interpretação e prática determina a relação de seu seguidor com ele. O modelo paulino, de crença (pistis) numa ação de qualidade salvífico-escatológica não é determinante aqui. No caso da Fonte $Q$, quando muito, esse caráter poderia ser atribuído à vitória do messias sobre o Diabo na tentação. Não se trata, desta forma, de afirmarmos qual desses modelos deve ser considerado original, mais próximo do Jesus Histórico. Trata-se de mostrar que a forma de organização da Fonte $Q$ e do Evangelho de Tomé nos permitem entender o modelo marcano como uma proposta de leitura, 
entre outras possíveis ${ }^{6}$.

\section{A narrativa pré-marcana da paixão como um modelo narrativo}

O modelo marcano, como vimos acima, não é o único, talvez nem mesmo o mais antigo. Que Jesus seja entendido como o messias-profeta justo, traído e perseguido pelos ímpios, cuja morte ocorre para remissão de pecados, e cuja justiça é vindicada por Deus na sua ressurreição, é um modelo narrativo que busca entender o destino de Jesus. A exegese histórico-crítica entende que o Evangelho de Marcos tem por base, como seu bloco mais antigo, a Narrativa Pré-Marcana da Paixão, ou seja, a redação da narrativa da paixão que foi fonte para Marcos. Não há porque rejeitarmos a hipótese da existência dessa narrativa de base, uma Vorlage, e do seu uso por Marcos ${ }^{7}$. No entanto, essa hipótese apenas indica que houve um paradigma interpretativo anterior a Marcos. Ela mesma, anterior ao mais antigo dos evangelhos, representa um modelo narrativo e de tradição martirológica que foi aplicado para a interpretação da morte violenta de Jesus de Nazaré. Esse caráter de modelo narrativo, de esquema interpretativo, fica evidente nos três anúncios da paixão do Evangelho de Marcos. A sequência de ações a que Jesus de Nazaré seria sujeito, segundo o terceiro e mais completo dos anúncios é: "Eis que subimos para Jerusalém, e o Filho do Homem será entregue aos chefes dos sacerdotes, e aos escribas; eles o condenarão à morte e o entregarão aos gentios, zombarão dele, e cuspirão nele, o açoitarão e o

6. Stephen J. Patterson, expoente dos estudos sobre o Evangelho de Tomé tem insistido no fato de Tomé, com sua antiguidade e composição não narrativa, em desconsideração da narrativa da paixão, colocar um problema para toda a história do cristianismo primitivo e para a prioridade do modelo paulino e sinótico, centrado na morte e na ressurreição. Cf. PATTERSON, S. J. The Gospel of Thomas and Christian Origins. Essays on the Fifth Gospel. Leiden: Brill, 2013; e em especial The Lost Way: How two Forgotten Gospels are Rewriting the Story of Christian Origins. New York: HarperOne, 2014.

7. Uma exposição sofisticada e detalhada desse estrato literário fonte pode ser conferida em PESCH, R. Das Markusevangelium II, Teil, Kommentar zu Kap. 8, 27 - 16,20. Freiburg: Herder, 1991, p. 1-27. 
matarão, e três dias depois ele ressuscitará" (Marcos 10, 33-34). Ocorre que se lermos o relato da paixão segundo Marcos, encontraremos esses mesmos elementos, essas sequências de ações, nessa mesma ordem. Não se trata, portanto, de um relato primeiro, pretensamente original, ele já segue esquemas narrativos, seleciona materiais, omite outros, ordena, faz citações e alusões intertextuais. Busca nas tradições do Antigo Testamento modelos de ordenação do que era entendido como caótico: a morte do Messias.

Após a morte de Jesus se instaurou uma profunda crise entre os primeiros seguidores de Jesus de Nazaré. Sua execução não era de fato esperada, não estava nos planos, pelo menos não mais do que uma possibilidade, afinal quem se propunha a realizar uma ação simbólica de purificação do Templo em plena festa da Páscoa devia contar com o risco de repressão das autoridades. Não devemos supor, no entanto, que isso estivesse desenhado com clareza para os discípulos, tanto que sua reação coletiva, cristalizada na traição de Judas e na negação de Pedro, foi no mínimo decepcionante: eles fugiram, se dispersaram, com exceção das mulheres. Após a morte de Jesus os discípulos teriam ficado escondidos, reclusos em Jerusalém, segundo os Atos dos Apóstolos, pelo menos até o derramamento do Espírito, no Pentecostes, quando eles passaram da oração reclusa para a pregação pública intrépida (cf. Atos 2, 14-47).

O processo de percepção - também poderíamos dizer, de reescritura - de quem é Jesus de Nazaré agora para eles, a despeito do escândalo de sua morte, de que Deus não interveio a seu favor em manifestações de juízo cósmico, é relatado de forma exemplar na cena da aparição do ressuscitado a dois discípulos no caminho de Emaús, em Lucas 24, 13 a 35. Jesus caminha com esses discípulos que seguiam em direção a Emaús. Eles não o reconhecem. Jesus Ihes explica que era necessário que o Messias padecesse e depois entrasse na Glória, segundo os profetas. E passa a lhes expor o destino do Messias começando por Moisés. Mas é na hora do partir do pão que eles o reconhecem. Essa 
cena é paradigmática. Resume anos de questionamentos, crise, dúvidas, desejo de abandonar tudo, até que os modelos narrativos amadurecem, que se toma consciência, pela leitura de outros textos, que o destino de Jesus, e deles mesmos, era o sofrimento. Foi por meio da explicação das Escrituras, ou seja, da descoberta de seus modelos narrativos, e da performance, do partir do pão, que o destino de Jesus de Nazaré é definitivamente transformado. É importante observarmos que ele não era um dado histórico, um fato positivo. Sem esses esquemas narrativos e interpretativos não falaríamos sobre ele hoje, ele ficaria esquecido como mais um dos milhares de galileus e judeus executados pela dominação romana. Se nos afastarmos um pouco do que é relatado - o que nos custa um pouco dada a beleza e sensibilidade da cena, observamos que as transformações histórico-tradicionais e cristológicas, se quisermos usar essa terminologia, não são ilustradas com o relato, elas acontecem na própria forma da narrativa, da reescritura. As personagens, as ações, o tempo, o espaço, são selecionados, combinados, ressignificados, de forma que Jesus de Nazaré ganha um novo sentido e se torna espaço de prática religiosa significativa.

\section{Martírio como motor literário:}

\section{outros gêneros gravitam em torno dos evangelhos}

Na exegese bíblica é comum termos um foco canônico. Nós segmentamos a literatura do cristianismo primitivo de forma a estudarmos apenas uma pequena parcela dela que foi considerada autorizada para o uso litúrgico, catequético e teológico pelos bispos da igreja do $4^{\circ}$ século. Anacronicamente transferimos essa seleção de textos, e a consequente desclassificação de todos os demais, para o estudo do cristianismo primitivo. Esse procedimento nos faz efetivamente ler um corpo literário muito menor de textos de uma religião nascente que tem como uma de suas maiores características a produção de textos. Isso é de fato surpreendente: que uma religião de subalternos, em uma sociedade na qual o letramento era restrito a poucas pessoas, praticasse uma 
intensa produção textual, em diferentes gêneros literários, alguns deles inclusive inventados por eles. O ponto central de nosso argumento é que, se a produção de textos, em especial narrativas, é uma das características principais do cristianismo nascente, não faz nenhum sentido estudar a religiosidade e as categorias culturais desse grupo por meio de uma amostra reduzida de seus textos. Das dezenas de evangelhos de que dispomos - na íntegra ou em fragmentos - lemos apenas quatro, das dezenas de Atos Apostólicos disponíveis, lemos apenas um. Não é possível justificar esse procedimento de análise histórica e literária em termos acadêmicos. Como lemos da documentação disponível apenas uma parcela, isso acaba acarretando distorções em nossa forma de análise. Entendemos fragmentos como o todo, fazemos generalização sobre um gênero literário a partir de evidências insuficientes. Pensamos, por exemplo, que o modelo sinótico quase corresponde ao Jesus Histórico, ou tomamos por certo que todas as comunidades cristãs têm o anúncio (kerigma) da morte e ressurreição como eventos salvíficos como seu eixo exclusivo da vida de Jesus de Nazaré. Também podemos imaginar, o que seria mais absurdo ainda, que a memória das tradições de Jesus chegou à completude nesses quatro evangelhos, e que o que se segue, segundo século adiante, é produto da imaginação sincrética e herética de comunidades marginais. Nada disso corresponde a uma compreensão histórica minimamente responsável sobre o processo de desenvolvimento da tradição dos evangelhos.

Uma das distorções que encontramos na pesquisa devido à desconsideração de um corpo textual mais amplo e perfeitamente disponível, foi apontada acima. Estudamos o gênero evangelho a partir de quatro evangelhos definidos como canônicos pelos concílios do $4^{\circ}$ século. Ao trazermos para a discussão o Evangelho de Tomé - e a Fonte $Q$, dentro da tradição sinótica - percebemos que o gênero evangelho é muito mais complexo do que imaginávamos. Não se trata mais de uma narrativa da paixão com "uma longa introdução" (isto é, todo o ensino de Jesus e os seus milagres), como se descreve jocosamente o gênero literário. Como 
o gênero é uma criação cristã e como está em construção, e como muito rapidamente encontramos variações nele, temos que reconhecer que "evangelho" é um gênero híbrido, com muitas subcategorias. Coleções de ditos, discursos do ressuscitado, relatos sobre a nascimento de Jesus, relatos sobre a história da mãe de Jesus, narrativas sobre a infância do messias, relatos sobre sua descida aos infernos durante sua morte, sua correspondência com Pilatos, com o rei Agbar, etc., todos esses formatos e enredos, fazem com que o relato que tem como "princípio" a sua morte salvífica seja apenas um tipo entre outros.

Mas suponhamos que o centro do gênero evangelho seja relatar e, portanto, ressignificar a vida de uma herói por meio de sua morte. De fato, o relato sobre o herói destinado à paixão é um subtipo de evangelho que merece nossa atenção, mas não somente por sua antiguidade, como pode ser atestada no Evangelho de Marcos ou na sua Vorlage (base textual), a Narrativa Pré-marcana da Paixão. Neste ponto temos que abandonar novamente o princípio de classificação canônica, do NT, mas também subverter as próprias classificações de gênero, uma vez que há aspectos que se entrecruzam entre os gêneros literários compondo um modelo cultural mais amplo. Há toda uma literatura cristã primitiva que tem como foco a morte do herói. Aliás, só se escreve sobre ele porque sua morte é uma referência simbólica para o universo de leitores desses textos: trata-se dos Atos Apostólicos Apócrifos. Nesta considerável coleção de textos são narradas as atuações dos apóstolos, desde seu envio pelo Cristo, por regiões geográficas (como João a Éfeso, André aos gregos, Tomás à Índia, entre outros), passando por suas viagens cheias de aventuras (naufrágios, encontro com animais ferozes, inimigos etc.), pela realização de milagres, conversão de matronas, conflitos com as autoridades até, por fim, seu martírio.

Christine Tomas, em sua obra The Acts of Peter, Gospel Literature, and the Ancient Novel. Rewriting the Past (THOMAS, 2003), nos chama a atenção para o fato que o modelo literário (ou o cronotópos, se quisermos assim chamar) do herói cujo sentido vai se desvelando ao longo de 
uma narrativa cujo fim é a sua morte violenta, segue sendo desenvolvido e projetado dos evangelhos para dentro de outros gêneros, como o prákseis (os Atos). Se pensarmos que os gêneros literários também são modelos de sociedade, ou modelos de ação na sociedade, como gêneros discursivos ${ }^{8}$, então temos que ler os evangelhos e seus modelos de construção de entendimento do Cristo, à luz desses outros relatos que retratam a vida de pessoas a partir de seu sofrimento, como diz Judith Perkins, como suffering self (PERKINS, 1995). Aqui a ficção literária passa a compor na cultura modelos de compreensão de mundo, formas de entender as relações com a sociedade, com o poder, representadas com categorias internas, recriando experiências de subalternos, constituindo espaço para desenvolvimento de subjetividade. Não podemos subestimar o poder cultural dessas narrativas que se articulam a partir do sofrimento do herói, de sua morte violenta.

Chama a atenção nos Atos Apócrifos a relativa ausência de referências a relatos sobre Jesus. É como se o modelo de seguimento dos discípulos do sofrimento do Cristo, deslocado na figura do apóstolo mártir os transformassem em pequenos cristos (MOSS, 2012). Nesse contexto, seria redundante retomar histórias de vida de Jesus e de seu martírio em obras que têm como protagonistas seus representantes, seus seguidores no sofrimento. Os apóstolos são então apresentados de forma ambivalente: são os destinados à morte que em vida realizam milagres poderosos, exibicionistas. Mas, a despeito de seu poder, conduzem suas vidas em pobreza, castidade, itinerância, em meio a perseguições, rumo à morte.

Os Evangelhos e os Atos Apócrifos abrem caminho para a construção de mais duas coleções consideráveis de textos: as Atas dos Mártires e a Vida dos Santos. As Atas dos Mártires aprofundam um degrau nessa caracterização da vida como sofrimento e como morte violenta. Nestes

8. Para o conceito de "gênero do discurso" ver BAKHTIN, M. Os gêneros do discurso (Organização, tradução, posfácio e notas de Paulo Bezerra). São Paulo: Editora 34, 2017. 
textos os protagonistas não são mais os apóstolos, muito menos o Cristo, mas homens e mulheres, cristãos e cristãs, que se distinguem pelo fato de sofrerem morte violenta, muitas vezes executadas com requintes de crueldade. Trata-se de um culto ao sofrimento, a uma extensão do sofrimento para além da excepcionalidade do destino salvífico do Cristo, único e especial, para algo que atingiu seus seguidores em tal intensidade que se torna modelo de narrar o mundo. O "quem não tomar a sua cruz e vir após mim" se torna um modelo consolidado de narrar o destino violento de seus seguidores e um discurso que articula a vida como sofrimento. Sofrimento passa de experiência quotidiana para valor religioso, que interpreta e caracteriza a forma como os cristãos avaliam sua relação com o mundo e sua devoção ao Cristo.

$\mathrm{Na}$ antiguidade tardia esses modelos narrativos são outra vez adaptados: eles se transformam na Hagiografia. Homens e mulheres santos, dentre eles apóstolos, eremitas, profetas, clérigos, todos vítimas de morte violenta ou de vida ascética no deserto (outra forma de mortificação), agem com poder e piedade no mundo, e seguem interferindo na vida dos viventes mesmo após a sua morte, seja em aparições, seja em suas relíquias.

Estamos nos afastando das reescrituras do Cristo? Sim e não. Apenas pretendemos mostrar que o gênero evangelho não era estanque, pré-definido, restrito ao material canônico, muito menos ao material sinótico. Também queremos mostrar que o enredo central dos sinóticos, a morte violenta do messias tem seu poder de orientação no mundo que extrapola o gênero evangelho, reinterpretando, reescrevendo a história de Jesus nas narrativas sobre a morte dos apóstolos e dos demais discípulos de Jesus, gente que sofre e é submetida à morte.

Como os gêneros literários Atos Apócrifos, Acta dos Mártires, e a Vida dos Santos, se apropriam, adaptam e desenvolvem o enredo de base dos evangelhos (o sentido da vida do herói determinado a partir de sua morte violenta), criando um discurso de sofrimento como um modo 
de vida, ou do sujeito sofredor, de forma semelhante esse enredo-base é projetado e deslocado 9 no longo tempo, se tornando um dos arquétipos literários mais importantes da literatura ocidental. Desta forma, podemos falar de reescrituras do Cristo em dois sentidos: a) no sentido estrito, de recriações da narrativa de Jesus do gênero evangelho, com todas as suas variantes mencionadas acima, e b) no sentido lato, de emulação de seus enredos de base deslocados em literaturas que não têm necessária referência ao Cristo e à sua história. Observem que o exemplo que dei acima, de reescritura que foca exclusivamente no enredo cuja vida adquire sentido a partir de sua morte, é apenas um modelo entre outros. Eu o escolhi para descentra-lo, para mostrar que o que se considera a definição de evangelho por excelência, como seu núcleo duro, é também submetida a esse processo dinâmico de reescritura. Poderíamos ter dado exemplos dessa emulação de enredo-base nos outros modelos de evangelho, como do herói que profere discursos reveladores de si mesmo e de sua missão antes de sua morte ou do herói que profere ditos curtos e ácidos questionando o status quo, ao estilo do profeta ou do sábio oriental. Todos esses elementos se projetam na literatura, na poesia, no teatro, no cinema, em fusão com outros enredos-base, bíblicos ou não.

\section{A atualidade da literatura apócrifa: apocrificidade como modelo de produção textual}

É necessário retornarmos uma vez mais ao problema da literatura apócrifa, a sua desconsideração sistemática em parte da academia, seja na teologia, na exegese bíblica, na história da antiguidade e nos estudos literários, em detrimento de uma seleção de textos sedimentada em concílios eclesiásticos do $4^{\circ}$ século. Creio que não há mais necessidade de argumentarmos a favor da inclusão de todos os evangelhos apócrifos no estudo dos diferentes modelos literários usados na construção da me-

9. “Displaced”, segundo Northrop Frye em Anatomy of Criticism. Four Essays. Princeton: Princeton University Press, 1990. 
mória de Jesus de Nazaré nas comunidades cristãs no mundo mediterrâneo antigo. O conceito apócrifo (apokryphos), que pode ser traduzido por "oculto, escondido, obscuro, difícil de entender"10, pode ser usado metaforicamente, a seu favor, para elucidação dos processos de produção de texto. Nesse caso teríamos que fazer uma transposição semântica: ao invés de pensarmos esses textos como marginais e excluídos por serem obscuros e de difícil compreensão, pensemos nessa característica, a que chamaremos de "apocrificidade", como a opacidade própria da linguagem religiosa, aparentada das densidades e plurivocidades do mito. Nesse sentido, citando Pierluigi Piovanelli em seu artigo What is a Christian Apocryphal Text and How does it Work: Some Observations on Apocryphal Hermeneutics (2005, p.31-40) e tomando a liberdade de lhe expandir o seu conceito "apocryphicity", podemos dizer que o evangelho de Marcos, o mais antigo, é já uma obra apócrifa, ou seja, uma obra que usa dos complexos recursos da narrativa para construir uma leitura de um personagem enigmático: Jesus de Nazaré. Um texto obscuro sobre um personagem enigmático. O que pode advir daí? Explosão de sentidos, de formas literárias, de inversões, mudanças de acentos, perspectivas, deslocamentos, condensações, complexos que vão da sátira ácida à opacidade redobrada do mito. E não só isso. Citamos Piovanelli em sua segunda provocação: da mesma forma que Marcos é a primeira obra apócrifa, o primeiro nessa construção mítica do personagem e de sua história, assim também é obra da apocrificidade o filme que em algum lugar do mundo está sendo gravado sobre Jesus de Nazaré, o poema que alguém está gestando em imagens na cabeça, o cântico que começa a ser balbuciado e dedilhado numa viola. Dos evangelhos à mais recente e experimental literatura, há uma profunda solidariedade nesse trabalho de elucidar um destino obscuro por textos densos, difí-

10. Essas são algumas das acepções de "Apókryphos" segundo Liddel, Henry George \& Scott, Robert. A Greek-English Lexicon. A New Edition. Oxford: Oxford at the Clarendon Press, 1958, p. 204. 
ceis, no desejo de trazer Jesus de Nazaré mais perto de nós ${ }^{11}$.

E a teologia, como reage a esses movimentos criativos? Com exceção das marginalizadas teologias que se ocupam da estética, impera uma estratégica rejeição dos modos narrativos de construção de mundo. As construções sistemáticas, as teologias dos métodos analíticos, abstraem o evangelho, antes de tudo uma narrativa, em proposições lógicas e práticas. Há um conflito na história do pensamento cristão entre imagem e conceito, entre narrativa e definição. Esse conflito é transferido para o Novo Testamento. É comum a interpretação que "evangelho" (euaggélion) é um conceito paulino, transformado em narrativa na tradição sinótica. Afinal Paulo mesmo se gaba de "não conhecer o Cristo segundo a carne", como equivalente à relativa ausência de referência aos milagres, ensinos, conflitos etc. de Jesus de Nazaré. Haveria um completo desconhecimento ou até mesmo desprezo por parte de Paulo de todo o material narrativo? Ou Paulo simplesmente não quer repetir os relatos de Jesus porque esse material é o capital simbólico daqueles que estiveram com Jesus desde o princípio, os doze? Paulo tinha que legitimar a todo o tempo sua autoridade como apóstolo do Cristo, como o qual, no entanto, só se encontrou com o ressuscitado. Curiosamente a esse encontro ele faz referência, ou melhor, ele o narra. Podemos desconstruir um pouco essa imagem anacrônica de Paulo como um primeiro teólogo conceitual, avesso a narrativas, se observarmos, em primeiro lugar, que o gênero literário com que se comunica com seus leitores é a carta, e que seus conteúdos tem que ver com administração da vida e de conflitos de suas comunidades, e, em segundo lugar, que seus escritos são sim perpassados de elementos narrativos. Faça a experiência de ler a Carta aos Romanos, não como um depósito precoce de dogmas, mas como uma grande narrativa mítica, que vai do primeiro ao segundo Adão, de Abraão à sua descendência, da consciência do pecado na lei e na contemplação da natureza, passando pela angústia do homem atormentado por

11. Mais dessa discussão em Nogueira, P. A. S. (ed.). Apocrificidade. O Cristianismo Primitivo para além do Cânon. São Paulo: Fonte, 2015, p. 15-37. 
sua impossibilidade de fazer o bem, até o anúncio da grande redenção cósmica. Romanos pode ser lido como um grande drama cósmico, no qual criação, paraíso perdido, vocação de Abraão, a entrega da lei, o desespero humano e a redenção desse e do cosmo constituem seus elementos organizadores. É tudo uma grande narrativa. Uma reescritura do Cristo. Ainda lemos os evangelhos, Paulo, enfim, o Novo Testamento com os olhos anti-narrativos do projeto hermenêutico da demitização.

\section{Considerações finais}

Por fim, queremos apontar para um último aspecto que deixaremos como perspectiva para a continuidade de nossa reflexão. Todo processo de produção de textos (texto no sentido amplo) não é autônomo. Ele depende de um outro polo onde os sentidos se efetivam. Trata-se do universo do leitor. Sem leitores os textos são artefatos inúteis, sem poder de comunicação. São leitores e leitoras concretos que efetivam e realizam o poder de criação de sentidos dos textos. Nesse sentido, nossa reflexão deve prosseguir com a análise das diferentes formas como os leitores atualizam e combinam as reescrituras do Cristo. Esses processos são complexos e ficam aqui apenas mencionados como um horizonte de pesquisa. Os processos de bricolagem, de criação de leituras caleidoscópicas devem ser consideradas nele. Um exemplo concreto: um leitor do Evangelho de Infância de Tomé no mundo antigo muito provavelmente também conhecia a narrativa Sinótica, a de Lucas, por exemplo. O que soa incompatível para o exegeta, para o historiador da religião, é combinado em conjuntos significativos pelos leitores antigos. Ou seja, ele não interpreta essas reescrituras do Cristo como incompatíveis, ao contrário, ele as harmoniza, criando uma terceira narrativa. Da mesma forma, a questão a se levantar é como esses processos de bricolagem acontecem no leitor contemporâneo. Como ele cria novas unidades significativas a partir de narrativas antigas (de diferentes tipos, incluindo as apócrifas, agora disponíveis aos leitores por meio de difusão na web) e contemporâneas? As recriações literárias passam a habitar 
o espaço da espiritualidade em conjunto, em diálogo com as narrativas antigas? Exemplo, um leitor que conhece a cena da crucificação de José junto com outros insurgentes nos arredores de Séforis, no Evangelho Segundo Jesus Cristo, de Saramago, reavaliaria a solidão da crucificação do Cristo nos evangelhos ${ }^{12}$. Ela deixaria de ser um evento único, isolado, especial, ainda que salvífico, para ser entendida num contexto ficcional e histórico, como um procedimento corriqueiro e cruel dos romanos contra os que ao império se opõem? A ficção de Saramago nos permite entender aspectos políticos subentendidos - ou ocultos? no texto de Marcos e na tradição sinótica? Ou como um leitor contemporâneo que lê os evangelhos como um conjunto, como uma narrativa em sua Bíblia, privadamente, mas também os relê em seu folheto "O Domingo" na missa, liturgicamente, e que, mais uma vez ainda os relê às terças feiras no Evangelho segundo Allan Kardec, com amigos no bairro? Que textualidades decorrem dessa composição de leituras que são percebidas pelo leitor como compatíveis e complementares? Desse conjunto de elementos, quais deles e como ele os atualiza para sua experiência social? E como novamente ele os identifica em um filme de Hollywood sobre Jesus de Nazaré que passa em sua TV no sábado de aleluia? Essas e outras questões devem pautar os estudos bíblicos no mundo contemporâneo.

\section{Referências bibliográficas}

BAKHTIN, M. Os gêneros do discurso (Organização, tradução, posfácio e notas de Paulo Bezerra). São Paulo: Editora 34, 2017.

BOYD, B. On the origin of Stories. Evolution, Cognition and Fiction. Cambridge, London: Belknap Press of Harvard University Press, 2009.

FRYE, N. Anatomy of Criticism. Four Essays. Princeton: Princeton University Press, 1990.

KAZANTZÁKIS, N. A última tentação. São Paulo: Grua livros, 2015.

KLAUCK, H-J. Evangelhos Apócrifos. São Paulo: Loyola, 2007.

12. Saramago, José. O Evangelho Segundo Jesus Cristo. São Paulo: Companhia das Letras, 1991. 
LIDDEL, H. G. \& SCOTT, R. A Greek-English Lexicon. A New Edition. Oxford: Oxford at the Clarendon Press, 1958.

MACK, B. O Evangelho perdido: o livro de $Q$ e as origens cristãs. Rio de Janeiro: Imago, 1994.

MEYER, M. O Evangelho de Tomé. As sentenças ocultas de Jesus. Rio de Janeiro: Imago, 1993.

MOSS, C. R. The Other Christs: Imitating Jesus in Ancient Christian Ideologies of Martyrdom. Oxford: Oxford University Press, 2012.

NOGUEIRA, P. A. S. Hermenêutica da Recepção: textos bíblicos nas fronteiras da cultura e no longo tempo. Estudos de Religião, vol. 26, no 46 (2012), p.15-31

PATTERSON, S. J. The Gospel of Thomas and Christian Origins. Essays on the Fifth Gospel. Leiden: Brill, 2013.

PATTERSON, S. J. The Lost Way: How two Forgotten Gospels are Rewriting the Story of Christian Origins. New York: HarperOne, 2014.

PERKINS, J. The Suffering Self. Pain and Narrative Representation in the Early Christian Era. London/New York: Routledge, 1995.

PESCH, R. Das Markusevangelium II, Teil, Kommentar zu Kap. 8, 27 - 16,20. Freiburg: Herder, 1991.

PIOVANELLI, P. What is a Christian Apocryphal Text and How does it Work: Some Observations on Apocryphal Hermeneutics, in: Theologisch Tijdschrift 59, p. 31-40, 2005.

SARAMAGO, José. O Evangelho Segundo Jesus Cristo. São Paulo: Companhia das Letras, 1991

SCHIAVO, L. A batalha escatológica na fonte dos Ditos de Jesus: a derrota de Satanás na narrativa da tentação (Q 4,1-13) - Tese doutoral Universidade Metodista de São Paulo. São Bernardo do Campo: 2003.

THOMAS, Chr. The Acts of Peter, Gospel Literature, and the Ancient Novel. Rewriting the Past. Oxford: Oxford University Press, 2003.

TURNER, M. The Literary Mind. The Origins of Thought and Language. Oxford: Oxford University Press, 1996.

VAAGE, L, Galilean Upstarts. Jesus' First Followers According to Q. Valley Forge: Trinity Press International, 1994.

VAAGE, L. O cristianismo Galileu e o evangelho radical de Q. Ribla, 22, Petrópolis: Vozes, p.84-108, 1995. 